\title{
A framework and workflow system for virtual screening and molecular docking
}

\author{
M Schumann*, M Röttig, NM Fischer, O Kohlbacher \\ From 6th German Conference on Chemoinformatics, GCC 2010 \\ Goslar, Germany. 7-9 November 2010
}

Virtual Screening and molecular docking usually require a large number of diverse and often incompatible programs. Problems arise when different programs require dissimilar file formats, are not available due to license issues, or have to be used in very different kind of ways. Furthermore, data is commonly not stored consistently and information about which tools were applied on which datasets in which way is usually lost.

Thus, in practice, frequent changes between tools and environments are necessary as well as - usually not lossless - conversions between different formats and results obtained this way are hard to reproduce.

Here we present a framework, based on the Biochemical Algorithms Library (BALL) [1], that provides a broad range of functionality, covering all common areas of interest for virtual screening and molecular docking. It includes tools for ligand/receptor preparation, interaction scoring, docking and rescoring, as well as for performing QSAR analysis and storage of molecules in a database.

This framework thus greatly facilitates the application of virtual screening and docking and consistent storing and handling of data.

Furthermore, all tools of our framework have been integrated into the workflow management system galaxy [2]. This way, the programs can be used directly from a webbrowser, without any need for programming skills or installation of tools on the part of the user. Workflows can be easily generated, stored and reused, which makes successive application of tools much easier. All data sets and uses of tools are automatically tracked and logged, so that results obtained by use of this system are easy to reproduce.

* Correspondence: schumann@informatik.uni-tuebingen.de

Zentrum für Bioinformatik, Eberhard Karls University of Tübingen, Germany
Published: 19 April 2011

\section{References}

1. Kohlbacher O, Lenhof HP: BALL-Rapid software prototyping in computational molecular biology. Bioinformatics 2000, 16(9):815-24.

2. Goecks J, Nekrutenko A, Taylor J, Galaxy: a comprehensive approach for supporting accessible, reproducible, and transparent computational research in the life sciences. Genome Biol. 2010, 11(8):R86.

doi:10.1186/1758-2946-3-S1-P15

Cite this article as: Schumann et al:: A framework and workflow system for virtual screening and molecular docking. Journal of Cheminformatics 2011 3(Suppl 1):P15.

\footnotetext{
Publish with ChemistryCentral and every scientist can read your work free of charge

"Open access provides opportunities to our colleagues in other parts of the globe, by allowing anyone to view the content free of charge."

W. Jeffery Hurst, The Hershey Company.

- available free of charge to the entire scientific community

- peer reviewed and published immediately upon acceptance

- cited in PubMed and archived on PubMed Central

- yours - you keep the copyright

Submit your manuscript here:

http://www.chemistrycentral.com/manuscript/

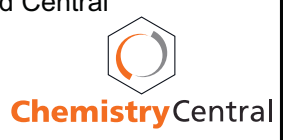

